\title{
VASIJAS CERÁMICAS PARA REDUCIR MINERALES DE COBRE EN LA PENÍNSULA IBÉRICA Y EN LA FRANCIA MERIDIONAL
}

\author{
LES CÉRAMIQUES À RÉDUIRE LE MINERAI DE CUIVRE DANS LA PÉNINSULE \\ IBÉRIQUE ET EN FRANCE MÉRIDIONALE
}

\author{
SMELTING CRUCIBLES TO REDUCE COPPER MINERALS IN THE IBERIAN \\ PENINSULA AND IN SOUTHERN FRANCE
}

\author{
SALVADOR ROVIRA (*) \\ PAUL AMBERT (**)
}

\section{RESUMEN}

Puesta en evidencia en España a finales de la década de los ochenta, la utilización de vasijas de cerámica común como recipiente de la metalurgia del cobre prehistórico ha sido identificada también en Francia. Los autores proponen una síntesis del estado de los conocimientos sobre el uso de esta técnica en España, su encuadre geográfico y cronológico y sus principales características mineralógicas y metalúrgicas. Estas últimas permiten mostrar la eficacia y la simplicidad de los medios puestos en juego para la realización de esta metalurgia inicial. En contrapartida, en Francia los hallazgos son todavía modestos y sólo unos pocos han sido objeto de los apropiados análisis de laboratorio. No obstante, la revisión de la documentación arqueológica sugiere que investigaciones específicas orientadas por los resultados expuestos en este artículo deberían permitir en Francia, como ha sucedido en España en el curso de los últimos años, poner de manifiesto el impacto de esta técnica durante las Edades del Cobre y del Bronce.

\section{RÉSUMÉ}

Mise en évidence en Espagne à la fin des années quatrevingts, l'utilisation de céramiques banales comme récipient de la métallurgie du cuivre préhistorique a été désormais repérée en France. Dans cet article, les auteurs proposent une synthèse de l'état des connaissances concernant l'utilisation de cette technique en Espagne, son cadre géographique et chronologique, ses principales caractéristiques minéralogiques et métallurgiques. Elles permettent de

(*) Museo Arqueológico Nacional. Serrano, 13. E-28001 Madrid. Correo electrónico: srl@man.es

(**) UMR 85555 CNRS, Centre d'Anthropologie. 39. Allées Jules Guesde. F-31000 Toulouse. Correo electrónico: m.p.ambert (a) wanadoo.fr

Recibido: 12-XII-2001; aceptado: 2-II-2002. montrer l'efficacité et la simplicité des moyens mis en jeu dans la réalisation de cette métallurgie précoce. En France, les données restent en contrepartie modestes, et n'ont fait que rarement encore l'objet d'analyses de laboratoire ad hoc. Néanmoins, la recension des documents archéologiques suggère qu'une recherche spécifique, éclairée par les résultats exposés dans cet article, devrait permettre en France, comme ce fût le cas en Espagne au cours des dernières années, de montrer l'impact de cette technique au cours des âges du Cuivre et du Bronze.

\begin{abstract}
As was shown in Spain by the end of the 1980s, the use of common earthenware vessels as containers for prehistoric copper metallurgy has also been discovered in France. The authors propose in this article a synthesis of the knowledge concerning the use of this technology in Spain, its chronological and geographical frameworks and the more relevant mineralogical and metallurgical features. All this allows us to show the effectiveness and simplicity of the resources used to practice this early metallurgy. The finds in France are more modest and rarely have been analysed properly in the laboratory. However, the review of the archaeological record suggests that specific research informed by the results presented in the article would provide evidence of the impact of this technology through the Copper and Bronze Ages.
\end{abstract}

Palabras clave: Vasijas de reducción. Metalurgia. Escorias de cobre. Calcolítico. Edad del Bronce.

Mots-clés: Céramiques à réduire. Métallurgie. Scorie. Chalcolithique. Âge du Bronze.

Key words: Smelting crucibles. Metallurgy. Copper slags. Chalcolithic. Bronze Age. 


\section{INTRODUCCIÓN}

Las vasijas reductoras de mineral de cobre han sido poco a poco puestas en evidencia en España a partir de las últimas excavaciones de Almizaraque (Cuevas del Almanzora, Almería) (Delibes et al., 1989) y, poco más tarde, con los hallazgos realizados en la región de Madrid (Rovira, 1989; Rovira y Montero, 1994). Indicios de una metalurgia que utilizaba estas vasijas desde comienzos del V milenio AC han sido señalados por Ruiz Taboada y Montero (1999).

El trabajo de campo, seguido de análisis de laboratorio y de reflexión en torno a las evidencias metalúrgicas, había de conducir a uno de nosotros (S.R.), desde 1986 (cf. infra, párrafo 2.1) a concebir y luego a demostrar la existencia de una metalurgia simple y eficaz que se realizaba con una mezcla de mineral de cobre y carbón reducidos a porciones pequeñas, puesta en una vasija abierta de cerámica común y llevada a la incandescencia mediante ventilación forzada en la parte interior del recipiente. Así nació la idea de la vasija-horno (Rovira, 1989). En menos de diez años se extendió por toda España apoyada en nuevos hallazgos, ha sido reconocida en Zambujal (Torres Vedras, Portugal) (Sangmeister, 1995) y luego en la Francia meridional (Ambert, 1997; Ambert y Carozza, 1997; Carozza, 1998).

En un trabajo precedente (Rovira y Ambert, 2002) se ha propuesto, en el marco de una Acción Integrada franco-española consagrada al estudio de este tipo peculiar de metalurgia (1), un amplio horizonte de difusión en Francia de estas vasijas y otros elementos con ellas emparentados. Este texto, más sintético pero con nuevas aportaciones, es una puesta al día para los lectores en lengua española.

\section{LAS VASIJAS DE REDUCCIÓN DE MINERALES DE COBRE EN ESPAÑA. ESTADO DE LA CUESTIÓN}

\subsection{Una revisión histórica}

A lo largo del siglo pasado se han ido publicando en la literatura arqueológica, con cierta frecuencia, hallazgos de hornos metalúrgicos en los pobla-

(1) El grupo francés, bajo la dirección de J. Vaquer, lo integran P. Ambert, L. Carozza, Ch. Servelle, B. Mille y C. Cert. El español, dirigido por G. Delibes de Castro, lo forman Ma' Martínez Navarrete, 1. Montero, J. Fernández Manzano, Miquel Molist y S. Rovira.

T. P., 59, n." 1,2002 dos calcolíticos y de la Edad del Bronce. Sin embargo, cuando se estudian con atención las descripciones uno se encuentra con simples estructuras de fuego atribuidas al trabajo del metal por asociación de vecindad con algún objeto metálico o con algún vestigio de actividad metalúrgica. Se consideraba que el horno metalúrgico debía ser una estructura relativamente grande, a menudo cupular. Las descripciones de Motos (1918: 57-60) de un hipotético horno en el Cerro de las Canteras (Vélez Blanco, Almería) o las de Siret (1948: 119) de otro de Almizaraque ejercieron una enorme influencia.

Cuando en 1982 se inició el Proyecto de Arqueometalurgia de la Península Ibérica bajo la dirección de Manuel Fernández-Miranda y Germán Delibes, uno de los primeros trabajos de laboratorio abordado fue el análisis de los materiales de Almizaraque conservados en las colecciones del Museo Arqueológico Nacional y en las del de Almería, a los que se añadirían los recuperados en las últimas excavacionés efectuadas por los mencionados profesores y su equipo en el poblado, a principios de los años 80 (Delibes et al., 1996). El interés particular de este yacimiento se cifraba en que teníamos representadas, y con suficientes muestras, varias fases del proceso metalúrgico de obtención de cobre:

- Fragmentos de mineral (malaquita, azurita, olivenita, etc.), caracterizados tras los análisis de su composición elemental y cristalográfica por un fuerte polimetalismo en el que destacaba su alto contenido de arsénico (Delibes et al., 1989: 91, tab. I).

- Porciones de mineral en estado de reducción parcial. Este tipo de hallazgo no había sido adecuadamente descrito en publicaciones anteriores. Suelen ser aglomerados de cuprita, de superficies redondeadas por fusión parcial durante el proceso de reducción (véase Delibes et al., 1989: 85, fig. 7).

- Numerosos nodulillos de metal (véase Delibes et al., 1989: 86, fig. 9).

- Abundantes fragmentos de vasijas cerámicas cuya cara interna estaba fuertemente afectada por efecto térmico, presentando escorificaciones, vidriado y, en ocasiones, pequeñas bolitas de cobre adheridas (véase Delibes et al., 1989: 89, fig. 11 y 12). Habitualmente se consideraban fragmentos de crisol.

Sin embargo resultaba muy chocante que, tanto en las excavaciones antiguas de Siret como en las más recientes, la cantidad de escoria encontrada era muy pequeña cuando, en buena lógica, la escoria es el subproducto más abundante de la obtención de cobre. La colección se limitaba a unos pocos frag- 
mentos pequeños de un material fuertemente coloreado de verde por las sales de cobre contenidas, difíciles de diferenciar a simple vista de los minerales o minerales parcialmente reducidos.

Otro problema todavía más exasperante era la inexistencia de estructuras identificables como hornos metalúrgicos. Coincidiendo en el tiempo con los estudios de los materiales de Almizaraque habían sido publicados los hornos calcolíticos del Sitio 39 de Timna en Israel (Rothenberg, 1985), cuyo modelo tratábamos de encontrar aquí sin éxito.

En el camino de la reflexión (que pasó por considerar que quizás los hornos estuvieron instalados en los alrededores, alejados del tell de Almizaraque para evitar la insalubridad de los humos arsenicados) recordamos un breve pero contundente estudio de Tylecote (1974), en el que demostraba la posibilidad de reducir malaquita directamente en un crisol. Como en el experimento se usó mineral muy puro, no se produjo escoria. Ahí podía residir la clave de la metalurgia de Almizaraque y la razón por la cual no encontrábamos ni hornos ni escorias. Así comenzaban a cobrar un nuevo sentido, también, los numerosos fragmentos de vasijas encontrados que exhibían escorificaciones cuprosas en su superficie.

Por otro lado, Zwicker et al. (1985: 103) habían documentado fragmentos de vasija con estas características en Çatal Hüyük (Anatolia), en un horizonte datado en el 7000-6000 AC, y se hacían eco de un crisol oblongo, con patas, y una punta de tobera del yacimiento calcolítico portugués de Pedra do Ouro (Leisner y Schubart, 1966), entre otros hallazgos, asociándolos a la producción de cobre. Los hermanos Siret también repararon en estos peculiares fragmentos de cerámica que encontraban con frecuencia en sus excavaciones y habían estado a punto de dar con la solución cuando escribieron que "no es probable que estos pedazos provengan de las vasijas en que la reducción debió hacerse, sino más bien de los recipientes destinados a recoger el cobre en pequeños lingotes..." (Siret y Siret, 1890: 63 ). Si se hubieran decantado por la primera opción habrían acertado de pleno.

Hemos de reconocer que en un primer momento, resistiéndonos a abandonar definitivamente la idea de la inexistencia de hornos metalúrgicos convencionales, pensamos que podrían ser fragmentos de camisas de la cámara del horno o vasijas que se introducirían a manera de crisoles en el interior del horno, y así lo propusimos en el Congreso sobre Minería y Metalurgia de las Civilizaciones Mediterráneas y Europeas, celebrado en Madrid en 1985
(Delibes et al., 1989: 88-89). Sin embargo, tras el estudio analítico en 1986 de un fragmento hallado en un yacimiento del Bronce Antiguo excavado por Concha Blasco en el Arenero de Soto (Getafe, Madrid), encontramos argumentos suficientes para hablar de las vasijas-horno (Rovira, 1989: 361), más acertadamente denominadas ahora vasijas o crisoles de reducción. En su interior tendría lugar el proceso completo de reacciones fisico-químicas que conducen a la obtención de cobre (Delibes et al., 1991: 306-307).

Habrían de pasar todavía algunos años hasta que otros investigadores de la metalurgia primitiva admitieran las evidencias de esta tecnología sencilla (Craddock, 1995: 133-134; Ambert, 1998: 6-7) y fuera documentada en otros lugares del Mediterráneo Oriental y Próximo Oriente (Hauptmann et al., 1996; Zwicker, 2000), en una fase tecnológica anterior al descubrimiento de la fundición escorificante controlada. En realidad, el empleo de vasijas para reducir minerales de cobre no puede ser considerado un hecho exclusivo de la Península Ibérica, aunque aquí se dio la curiosa circunstancia de haber estado en uso desde el Neolítico Medio (Ruiz Taboada y Montero, 1999) hasta finales de la Edad del Hierro (Gómez Ramos, 1999).

\subsection{Los contextos arqueológicos}

El número de yacimientos en los que se registra la presencia de vasos de reducción aumenta constantemente en nuestro país, conforme avanzan los trabajos arqueológicos o las revisiones de materiales de antiguas excavaciones. El mapa de la figura 1 ilustra los principales hallazgos correspondientes a las fases más antiguas, desde el Neolítico al Bronce Medio. Para épocas más recientes puede consultarse el trabajo de síntesis de Gómez Ramos (1996b) o el caso concreto de la metalurgia castreña (Fernández-Posse et al., 1993). En el mapa aparece vacío el cuadrante noroccidental de la Península, hecho que esperamos vengan a subsanar nuevas investigaciones. Los contextos arqueológicos de los sitios mencionados son conocidos, y han sido sistematizados recientemente en Delibes y Montero (1999).

El poblado neolítico de Cerro Virtud de Herrerías (Cuevas del Almanzora, Almería) ha proporcionado el fragmento de vasija más antiguo actualmente conocido. Está asociado a un nivel arqueológico datado en $5830 \pm 90 \mathrm{BP}$ (Beta- 


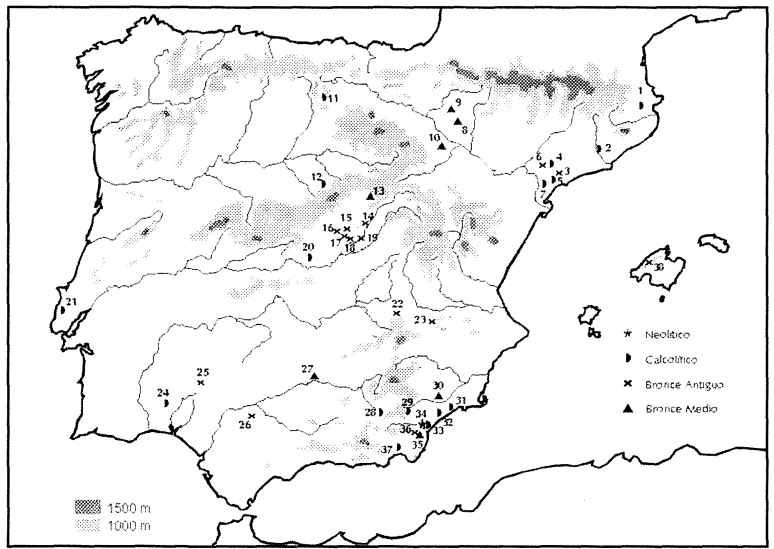

Fig. 1. Mapa con la distribución de los yacimientos donde se han registrado hallazgos de fragmentos de vasos de reducción de minerales de cobre (diseño de I. Montero): 1 Bauma del Serrat del Pont, 2 Cova del Frare, 3 Cova del Cartanya, 4 Balma del Duc, 5 Cova del Buldó, 6 Coveta de l'Heura, 7 Cova Josefina, 8 Puy Aguila, 9 Monte Aguilar I y II. 10 Moncín, 11 Cueva Rubia, 12 Cueva de la Vaquera, 13 Loma del Lomo, 14 Matillas, 15 El Ventorro, 16 Villaviciosa de Odón, 17 Camino de la Yesera, 18 Arenero de Soto, 19 Carabaña 35/40, 20 Fontarrón, 21 Zambujal, 22 Morra del Quintanar, 23 El Acequión, 24 Cabezo Juré, 25 Trastejón y Puerto Moral, 26 El Acebuchal, 27 Llanete de los Moros, 28 Cerro del Prado, 29 El Malagón, 30 La Bastida, 31 La Ceñuela, 32 Parazuelos, 33 Almizaraque, 34 Cerro Virtud, 35 El Argar, 36 Lugarico Viejo, 37 Los Millares, 38 Son Matge.

118936), 4915-4475 cal AC a $2 \sigma$ (Ruiz Taboada y Montero, 1999: 900). Los análisis preliminares efectuados a la escorificación detectaron cobre, plomo y antimonio, metales que se encuentran en una mineralización explotada hasta hace unos años, situada a muy poca distancia del yacimiento, en el propio cerro (Montero y Ruiz Taboada, 1996: 71).

No es ahora momento de entrar a discutir las implicaciones metalúrgicas del hallazgo de Cerro Virtud que, por otro lado, ya han sido planteadas por Delibes y Montero (1997) y Rovira (e.p.a), pero no podemos dejar de mencionar la elevada probabilidad de que la Península Ibérica, o en términos más globales los territorios del Mediterráneo occidental, fueran un área de invención metalúrgica en fechas tan tempranas como el V milenio cal AC.

Existe de momento un largo hiato entre Cerro Virtud y la eclosión de la metalurgia calcolítica a finales del IV milenio y comienzos del III en fechas calibradas. Son de sobra conocidos los yacimientos de Zambujal (Torres Vedras, Portugal) y Los Millares (Santa Fe de Mondújar, Almería), tenidos por paradigmas -que habría que revisar- de las culturas de la Edad del Cobre. Sin embargo, el estudio arqueometalúrgico más completo realizado hasta ahora desde esta nueva perspectiva es el de Almizaraque, al que nos dedicaremos más extensamente en el apartado siguiente.

Cabezo Juré (Alosno, Huelva), excavado recientemente bajo la dirección de Francisco Nocete (2001: lám. 15-21), se configura como otro de los yacimientos del final del Calcolítico más interesantes desde el punto de vista metalúrgico por la abundancia de materiales recuperados, conectados con actividades de obtención y trabajo del cobre. Las primeras etapas metalúrgicas de la región del Suroeste eran prácticamente desconocidas (Gómez Ramos et al., 1999; Hunt y Hurtado, 1999), a pesar de sus enormes depósitos minerales que forman una ancha faja metalífera que recorre las provincias de Sevilla y Huelva y se adentra en el sur de Portugal. La investigación arqueometalúrgica de Cabezo Juré éstá muy avanzada y esperamos que pronto pueda ser expuesta en letras de molde (2). Podemos anticipar que han aparecido numerosos fragmentos de vasos de reducción junto a grandes estructuras de fuego cilíndricas, con tipos de vasija que son más propiamente bandejas que cuencos (parecidos a las "lingoteras" de Zambujal), aunque también existen éstos.

El empleo de vasos de reducción en el Bronce Antiguo está ampliamente documentado. En los alrededores de Madrid, las evidencias más numerosas se han recogido en El Ventorro (Villaverde), de época campaniforme. Otra bien contextualizada es la del Arenero de Soto. Todas ellas fueron objeto de minuciosos estudios efectuados por Rovira y Montero (1994). A ellas hay que añadir las del Camino de la Yesera en Getafe (Gómez Ramos, 1998).

La continuidad del uso de esta técnica en el Bronce Medio está bien atestiguada por los hallazgos en yacimientos de la cultura de El Argar, en el Sureste, como los del propio Argar en Almería y los de La Bastida de Totana en la provincia de Murcia. Más al norte, en el valle del Ebro, se han estudiado fragmentos de vasos de reducción de Monte Aguilar I y II (Navarra) y existen también en Moncín (Zaragoza).

Particularmente interesante es el yacimiento de la Bauma del Serrat del Pont (Tortellà, Girona), un

(2) En el IV Congreso Nacional de Arqueometría celebrado en Valencia en septiembre de 2001 se presentaron dos comunicaciones sobre este yacimiento: Rovira et al. (2001) y Sáez et al. (2001).

T. P., 59, n. ${ }^{\circ} 1,2002$ 
pequeño hábitat con una ocupación continuada que se inicia en el III milenio cal AC y se prolonga en el Bronce Antiguo. Es el yacimiento que mayor número de fragmentos de vasos de reducción ha proporcionado hasta el momento, con un total de 65 bien identificados y algunos otros dudosos. De la reciente revisión y estudio de estos materiales (Alcalde et al., 1998) conviene destacar una punta de flecha de bronce cobre-estaño ( $7 \% \mathrm{Sn}$ ) fechada en el $4020 \pm 100$ BP (Beta-64939) y un vaso en cuya costra de escoria se ha detectado un 7,6\% de estaño, además de cobre y otros elementos. Los autores especulan sobre la posibilidad de que la punta sea de un bronce obtenido accidentalmente si se acepta la explotación de los minerales polimetálicos cobre-estaño de las minas de La Ferrera y Can Manera, distantes pocos kilómetros de la balma. No parece dudarse de la producción deliberada de bronce en la fase siguiente fechada en torno al 3840

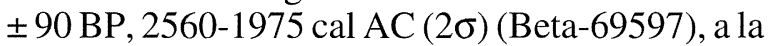
que pertenecen un nódulo metálico, una aguja o punzón y un fragmento de vasija con escorificaciones conteniendo cobre y estaño. Esto sugiere que el vaso fue utilizado para producir directamente bronce mediante la reducción conjunta de mineral de cobre y casiterita, una técnica cuya viabilidad ha sido comprobada experimentalmente por Rostoker y Dvorak (1991). La Bauma del Serrat del Pont se erige así en el yacimiento con la fecha más antigua para la producción de bronces en la Península Ibérica. Por otro lado, es también el yacimiento más cercano al Midi de Francia, un cato que conviene retener.

Tenemos evidencias de que el mismo proceso de reducción conjunta de minerales de cobre y estaño se utilizó también en la transición Bronce Antiguo-Bronce Medio a través de los fragmentos de vasos de reducción de Monte Aguilar (Rovira et al., 1997: 281-282), datados en el $1560 \pm 20 \mathrm{aC}$ (GrN-19671) (Fernández-Miranda et al., 1995: 63; Sesma, 1995: 153).

Las formas de las vasijas utilizadas para la obtención de cobre debieron ser muy variadas. Se han podido reconstruir algunas a partir de sus fragmentos resultando ser de boca muy abierta y poca altura; una especie de cazuelas o cuencos (Montero, 1993: 51, fig. 3). La de mayor tamaño que hasta ahora hemos podido estudiar y reconstruir tiene un diámetro cercano a los $50 \mathrm{~cm}$ y procede del yacimiento calcolítico de La Ceñuela (Mazarrón, Murcia). En poblados donde el registro arqueológico permite buenas comparaciones, como Almizara- que, El Ventorro o la Bauma del Serrat del Pont, no parece que los vasos de uso metalúrgico se diferencien ni por su forma ni por la composición de la arcilla de las vasijas domésticas de diseño similar (Rovira y Montero, 1994: 160-161). Son ya bastantes los hallazgos de fragmentos con decoración campaniforme, lo que corrobora que, en un momento dado, cualquier recipiente cerámico abierto puede servir. Sin embargo, algunos de Cabezo Juré cuyo aspecto es el de bandejas oblongas con bordes engrosados que apenas se elevan unos centímetros del fondo plano (Nocete, 2001: lám. 17 y fig. 45) podrían representar enseres específicos para este uso metalúrgico.

Los crisoles para fundir metal, en cambio, son muy distintos de los vasos de reducción. Tienen una capacidad en general mucho menor y sus paredes son más gruesas. Suelen presentar escorificaciones por el interior y vidriado de la cerámica por los bordes y zonas de la superficie externa.

\subsection{Análisis de restos metalúrgicos asociados a las vasijas de reducción}

La serie completa de productos y subproductos de la fundición de minerales de cobre comprende, como ya se ha dicho, minerales, minerales parcialmente reducidos, escorias, vasos de reducción, gotas de metal bruto y objetos acabados. Desde el punto de vista metodológico, los estudios de laboratorio encaminados a establecer los procesos tecnológicos de obtención de metal requieren la utilización de diverso instrumental de laboratorio cuyos resultados analíticos, combinados entre sí, permitirán alcanzar el máximo conocimiento de los materiales. Un instrumento de enorme eficacia para estos estudios arqueometalúrgicos es el microscopio electrónico de barrido (MEB) equipado con microanalizador por fluorescencia de rayos $\mathrm{X}$ y detector de electrones retrodispersados (back scattering). Al mismo tiempo que proporciona la imagen visual por medio de una imagen virtual dibujada en función de la composición química del material en observación (fases estructurales), permite, por medio de la microsonda, determinar instantáneamente la composición química elemental de las fases de interés. Estas posibilidades de individualización son imprescindibles en el estudio de las costras de escoria de los vasos de reducción y de las escorias calcolíticas, dada la extraordinaria complejidad de las mismas, en nada parecidas a las 
escorias convencionales que resultan de tecnologías más avanzadas de fusión escorificante ayudada de fundentes (Hauptmann et al., 1996; Rovira y Gómez Ramos, 1998). La absoluta falta de homogeneidad de los materiales escoriáceos hacen poco útiles los análisis globales como indicadores de la naturaleza de la escoria, siendo de mucha mayor utilidad la identificación de las fases constituyentes por estar directamente relacionadas con los problemas tecnológicos que tratamos de resolver.

Como ejemplo de lo antedicho, simplificado para ajustarnos a la extensión de este artículo, se comentarán a continuación los últimos resultados obtenidos con muestras del yacimiento calcolítico de Almizaraque.

\section{Minerales}

Durante las excavaciones de la década de los ochenta se recogieron fragmentos de mineral de cobre, con aspecto de malaquita y azurita, a los que se practicó un primer análisis elemental, resultando muchos de ellos ser extraordinariamente ricos en arsénico (Delibes et al., 1989: 91, tab. 1). Algunas de estas muestras arsenicales fueron analizadas posteriormente por difracción de rayos X, detectándose, además de los carbonatos de cobre, arseniatos como la olivenita (Montero, 1994).

Cuatro muestras de mineral han sido analizadas con la microsonda del MEB (3). La riqueza en cobre, calculada como tenorita, es elevada, oscilando entre $21,3 \%$ y $81,2 \%$. No se detecta azufre, lo que confirma que se trata de especies no sulfuradas.

El polimetalismo de estos minerales es evidente, destacando el arsénico por su interés en los resultados de la reducción, que oscila entre $2,7 \%$ y 9,4\% calculado como trióxido. El arsénico se encuentra en forma de arseniato, bien como olivenita, bien como conicalcita.

Ninguno de estos minerales es autofundente, es decir, que las proporciones de sílice y hierro en la ganga no son las adecuadas para que, al fundir, se produzca una escoria fayalítica de bajo punto de fusión. Lo que cabe esperar de la fusión reductora es la formación de una cantidad de material escoriáceo complejo, con silicatos y óxidos de alto punto de fusión (teórico). A partir de la riqueza estima-

(3) Todos los análisis han sido efectuados en el microscopio electrónico de barrido del Servicio Interdepartamental de Investigación de la Universidad Autónoma de Madrid, operado por la microscopista Esperanza Salvador Rueda. da en cobre se puede deducir que la cantidad de escoria producida oscilaría entre el $20 \%$ y el $40 \%$ en peso del mineral cargado en el vaso, una cantidad nada despreciable que, por cierto, no aparece en el registro arqueológico.

Algunos minerales contienen inclusiones de metales pesados como la plata, el plomo y el bario. Este último pasará a la escoria pero la plata y parte del plomo se incorporarán al cobre, siendo responsables de las trazas de estos elementos que habitualmente se han detectado en los objetos de metal de Almizaraque (Rovira et al., 1997: 58-62).

\section{Minerales parcialmente reducidos y escorias}

Los minerales parcialmente reducidos, reconocibles por sus formas redondeadas, pueden a veces confundirse a simple vista con las pequeñas porciones de escoria ricas en mineral porque externamente tienen la misma coloración verde de las sales de cobre. Por esa razón solemos agruparlas en el mismo conjunto, discriminando tras el análisis las escorias por su menor contenido en cobre. En esta ocasión se han analizado tres muestras. En este material se forman fases similares a las de las escorias (piroxenoides, akermanita, etc.) pero en menor proporción. El efecto reductor se deja sentir en ellas, de modo que con frecuencia contienen bolas microscópicas de metal.

El complejo efecto de las alteraciones termoquímicas puede observarse en la muestra ALMIZ-322 , cuyo análisis global indica que es un mineral de cobre con un fuerte contenido de arsénico (13,8\% de $\mathrm{As}_{2} \mathrm{O}_{3}$ ). En la lámina I se advierten los grandes cristales de cuprita (color blanco) que, vistos a menores aumentos, tiene la forma dendrítica característica. En los intersticios se han formado cristales tabulares y aciculares (color gris claro) cuyos principales componentes son compuestos oxigenados de calcio, cobre y arsénico que recuerdan la estructura de la conicalcita (arseniato de cobre y calcio) con una notable sustitución de cobre por calcio. Finalmente, la matriz de color gris oscura es un vidrio silicatado en el que se concentra calcio, hierro, cobre y arsénico principalmente.

La muestra ALMIZ-13 es muy representativa de esa situación intermedia entre mena y escoria, además de ilustrar ciertas condiciones de trabajo del vaso de reducción. La lámina II muestra un área en la que se ha formado una masa de metal grande (relativamente) y otras más pequeñas. El metal es cla- 


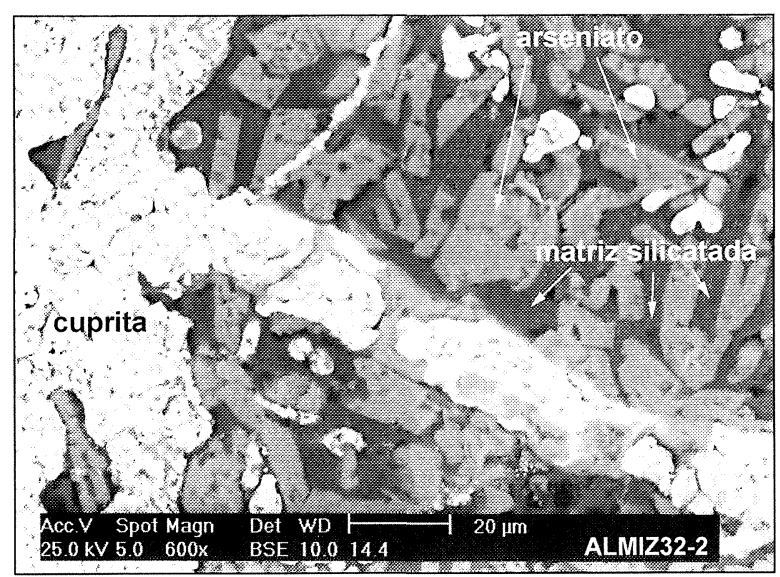

Lám. I. Imagen obtenida en el MEB de la muestra ALMIZ32-2. Mineral parcialmente reducido. Explicación en el texto.

ramente bifásico, con unas zonas blancas en las que el arsénico alcanza un valor del 18\% (ALMIZ-13/ 3 ) y otras más grisáceas con un $5,2 \%$ de este elemento (ALMIZ-13/2). El metal está rodeado por una matriz de akermanita y numerosos cristales de magnetita (u óxido de $\mathrm{Fe}^{+3}$ ) fácilmente reconocibles por sus formas geométricas. En primer lugar, nos hallamos ante una evidencia de la producción de cobre arsenical cuya intencionalidad por parte del fundidor es más que dudosa ya que viene condicionada por la composición del mineral que lo origina. En segundo lugar, la abundancia de magnetita es una prueba evidente de que las condiciones ambientales en el interior de la vasija de reducción fueron poco reductoras por no decir que más bien

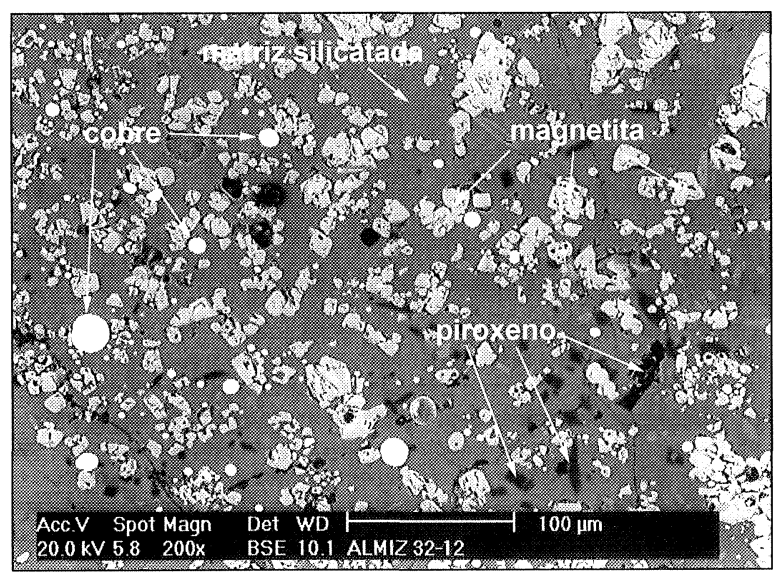

Lám. III. Imagen obtenida en el MEB de la muestra ALMIZ-32-12. Escoria. Explicación en el texto.

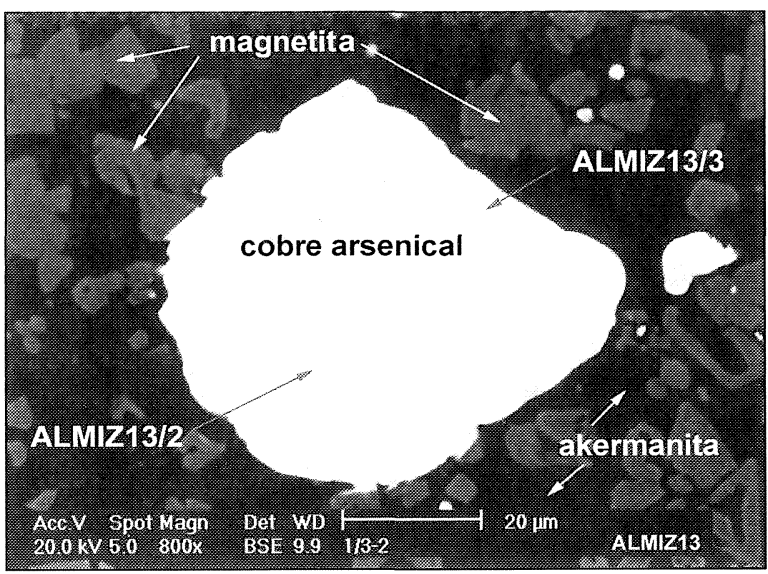

Lám. II. Imagen obtenida en el MEB de la muestra ALMIZ13. Mineral parcialmente reducido o escoria. Explicación en el texto.

oxidantes. Solamente en un ambiente oxidante el óxido ferroso de la ganga se puede convertir en magnetita. Parece, pues, que durante el procesamiento del mineral en el recipiente hay fases oxidantes, quizás durante el avivado de las brasas de carbón para subir la temperatura, que provocan este efecto y el balance temperatura-tiempo-presión de monóxido de carbono forma un sistema crítico poco eficiente. O, dicho con otras palabras, que estamos ante un método de producción de cobre muy primitivo que funcionaba gracias a que la presión necesaria del agente reductor (monóxido de carbono) es muy baja, con una entalpía libre de formación del metal también pequeña, como se deduce del diagrama de Ellingham.

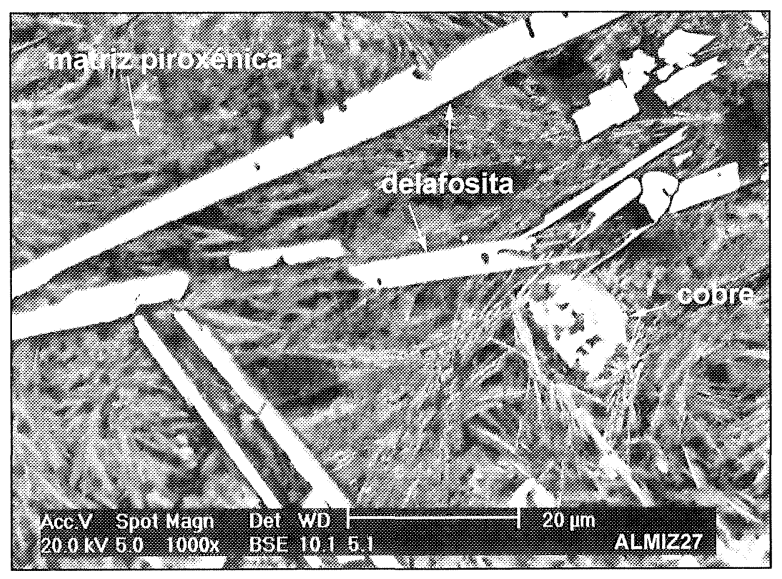

Lám. IV. Imagen obtenida en el MEB de la muestra ALMIZ27. Escorificación en vasija de reducción. Explicación en el texto. 
Las escorias retienen mucho cobre, bien en forma de mineral o de nodulillos de metal atrapados. La lámina III corresponde a la microestructura de la escoria ALMIZ-32-12. En ella pueden apreciarse algunas de las características de las escorias calcolíticas como son una matriz habitualmente silicatada, cristales de óxido de hierro trivalente (con frecuencia magnetita) y, en ocasiones, cristalizaciones de piroxeno, akermanita, monticellita y otros silicatos. Abundan las bolitas de metal, a veces envueltas por coronas de cuprita o de calcosina, con composiciones elementales muy variables dentro de la misma muestra. También es frecuente encontrar granos de sílice sin reaccionar.

Escorias en la pared de vasos de reducción de minerales de cobre

La costra de escoria que se forma en la cara interna de la pared del vaso de reducción está fuertemente adherida a la superficie cerámica. De hecho forma cuerpo con ella y en muchas ocasiones la frontera de separación es difusa, siendo frecuente la formación de una capa intermedia de transición entre la escoria y la cerámica intacta, mostrando distintos grados de afectación térmica (vitrificación) y diferentes composiciones químicas a lo largo de su sección. A elevada temperatura, los minerales de cobre en contacto con la pared de cerámica reaccionan con los silicatos y el óxido de hierro formando una escoria rica en sílice que suele ser poco homogénea en estructura y composición, y en cuyo seno casi siempre podremos observar pequeñas bolas de cobre.

Entre los componentes de las fases de la escoria encontramos silicatos de alto punto de fusión como los piroxenos y piroxenoides, la akermanita y la anorthita. Es frecuente la presencia de granos de sílice sin disolver, aunque a menudo muestran contornos redondeados que indican su participación en la formación de los compuestos silicatados.

La lámina IV muestra un campo característico de la muestra ALMIZ-27. En una matriz piroxénica de formas fibrosas se han formado bellas agujas blancas de delafosita. Este compuesto, con una temperatura de formación en torno a los $1.150^{\circ} \mathrm{C}$, es un excelente indicador de la temperatura de trabajo del vaso de reducción. Es, además, un compuesto estable en ambiente oxidante, por lo que su presencia es otra evidencia de que el proceso cursa con periodos de atmósfera rica en oxígeno naciente.
La composición de las bolas metálicas formadas en la escoria nuevamente nos demuestra la producción de cobre arsenical en muchos casos.

\section{Nódulos de cobre bruto}

El resultado final de la operación es la obtención de cobre en porciones cuyo tamaño debía ser muy variable: desde masas de cerca de $100 \mathrm{~g}$ de peso como alguna hallada en Almizaraque hasta pequeñas bolas microscópicas. La recuperación del cobre debía hacerse triturando el producto de la fundición con la ayuda de martillos de piedra, de cuya presencia en los yacimientos hay numerosas evidencias. Efectivamente, la escoria es excesivamente viscosa a la temperatura de trabajo para permitir una buena separación del metal por diferencia de densidades. Mediante la operación de triturado, además de separar el metal se podía recoger el mineral sin reducir para utilizarlo en una nueva fundición. Esta es otra razón por la cual las escorias encontradas son tan escasas.

Los análisis efectuados a varios nódulos de metal han dado composiciones muy variables. Aunque alguno es de cobre, lo más frecuente es que encontremos cobres arsenicales dentro de un rango de arsénico que oscila entre $2,6 \%$ y $4,9 \%$. Suelen contener inclusiones microscópicas de metales pesados (plata, antimonio, plomo, bismuto). El contenido medio en hierro es relativamente alto en comparación con el de los objetos acabados, lo cual no debe sorprendernos porque gran parte de este hierro se perderá al refundir en el crisol estas porciones de metal, resultando una colada de cobre más refinado. También se perderá una parte importante del arsénico. Aproximaciones al modelo teórico de la transformación del mineral en metal de Almizaraque han sido expuestas en Delibes et al. (1991: 305306), Montero (1994: 232-235) y Gómez Ramos (1999: 62-63).

Los nódulos y gotas de metal de Almizaraque pudieron tener dos orígenes distintos. Unas se habrán formado en la vasija de reducción y otras serán gotas caídas del crisol durante las operaciones de llenado del molde, al fabricar una pieza colada. En teoría, las primeras, al formarse a alta temperatura y someterse al enfriamiento lento del material contenido en la vasija una vez terminado el proceso, deberían presentar una microestructura con el metal recristalizado. Las segundas, en cambio, al pasar rápidamente del estado líquido en el crisol al

T. P., 59, n. ${ }^{\circ} 1,2002$ 


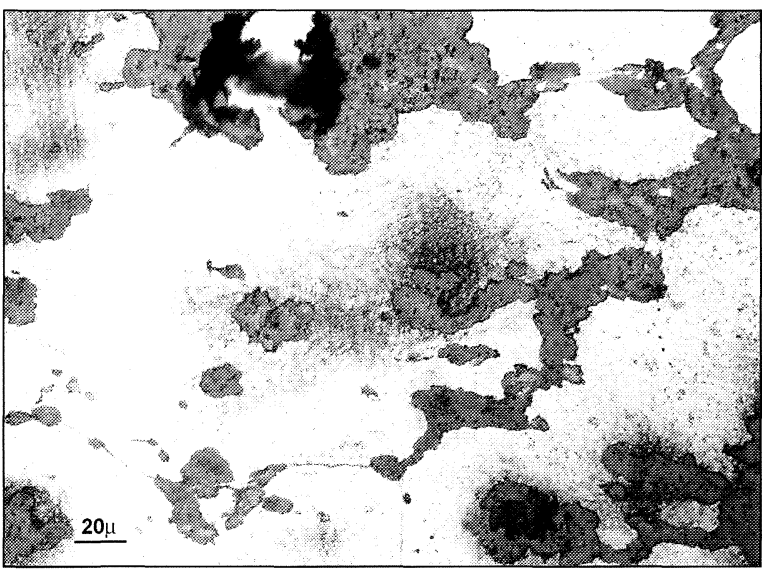

Lám. V. Metalografía del nódulo de cobre ALMIZ-5-6. Explicación en el texto.

sólido en tierra, su microestructura será siempre de bruto de colada. La lámina $\mathrm{V}$ es una imagen metalográfica de la gota ALMIZ-5-6. En ella podemos apreciar el metal recristalizado, formando grandes granos cuyos bordes se aprecian en la parte inferior como una delgada línea quebrada. Lo más interesante de esta metalografía es que también se ven claramente numerosas estrías de deformación en frío (series de líneas muy finas, más perceptibles en el centro de la imagen y en el ángulo superior izquierdo). En nuestra opinión, esa deformación se produjo en la operación de machacado de la escoria para separar el metal y sirve como demostración de que ése era el tratamiento habitual de las escorias.

\subsection{A manera de síntesis}

El funcionamiento de los vasos de reducción es en esencia sencillo: el mineral machacado se agregaba a las brasas encendidas de carbón vegetal y es probable que más carbón y mineral se fueran agregando hasta completar la carga. En Almizaraque, Las Angosturas y en otros poblados calcolíticos se han encontrado pequeñas bolsadas de mineral triturado, a veces mezclado también con carbón.

Los pasos concretos del proceso no son del todo conocidos. En especial existen lagunas en la fase termodinámica de la reducción propiamente dicha. Es de suponer que hubiera una fase de precalentamiento de la vasija, aunque sólo fuera para encender bien las brasas de carbón. Ya hemos visto por los estudios de las escorificaciones y otros subproduc- tos que se alcanzaban en el interior de la vasija temperaturas del orden de 1.100 a $1.200^{\circ} \mathrm{C}$. La formación de cuprita dendrítica, delafosita y otros compuestos así lo indican claramente. También es de sobra conocido que el problema no es alcanzar esas temperaturas sino mantenerlas. Mediciones realizadas en trabajos experimentales indican que, cuando se utilizan tubos de soplado a pulmón (blow-pipes), el punto aireado llega a alcanzar los $1.200^{\circ} \mathrm{C}$ pero la temperatura desciende drásticamente hasta los $800^{\circ} \mathrm{C}$ cuando se deja de soplar (Hauptmann et al., 1996: 6). Esto produce continuas oscilaciones de las condiciones redox en distintos puntos del sistema. De hecho, la formación de delafosita tiene lugar a alta temperatura en presencia de magnetita (producida por oxidación del óxido ferroso en los períodos de ambiente oxidante) y cuprita.

Los estudios petrográficos de los componentes cristalinos de la cerámica de la vasijas de reducción indican que nó se superaron nunca los $1.000^{\circ} \mathrm{C}$ en el núcleo de la pared del vaso (Gómez Ramos, 1999: 183). Este es un dato interesante, teniendo en cuenta lo dicho antes, pues confirma que el foco calorífico principal estaba en el interior de la vasija, no en el exterior. Ante la escasez de toberas en los yacimientos calcolíticos excavados hasta entonces, Gómez Ramos (1996a) ya supuso que se usaba como alternativa los tubos de soplado o el flujo natural del viento. Recientemente se han publicado dos fragmentos de toberas de los niveles fechados en el III milenio cal AC del yacimiento de la Bauma del Serrat del Pont (Alcalde et al., 1998: 9192) que se añaden a la ya conocida de Pedra do Ouro y al fragmento de Buraco da Pala (Comendador, 1998: 112), abriendo la posibilidad de que el sistema convencional de toberas accionadas por fuelles fuera también un procedimiento de uso más antiguo y común de lo que se había supuesto.

El producto final de la fundición debía estar formado por una masa heterogénea en la que se mezclaban minerales parcialmente reducidos y gotas de metal aglutinados por la escoria. Quizás fuera necesario romper la vasija si esta masa se quedaba pegada a la cerámica. Para separar el metal había que triturar el material, como ya se ha dicho antes.

\section{LA IMPORTANCIA DE LA VÍA EXPERIMENTAL}

El primer experimento moderno de fundición directa de minerales en una vasija fue realizado en 
el Arqueódromo de la Borgoña (Francia), en el verano de 1996, durante unas jornadas de experimentación organizadas por M.Ch. Frère-Sautot (4). Jacques Happ elaboró un cuenco de base plana con arcilla refractaria, de unos $15 \mathrm{~cm}$ de diámetro y 5 $\mathrm{cm}$ de altura, con paredes gruesas de unos $2 \mathrm{~cm}$ de espesor. En su interior se colocó mineral de cobre (malaquita y azurita) en fragmentos de más de 5 $\mathrm{mm}$ de tamaño mínimo. Sobre la vasija, cubriéndola completamente, se encendió un fuego de leña al que se le fue agregando carbón hasta conseguir buenas brasas, avivadas por el viento forzado de un ventilador industrial que producía una corriente de aire con una velocidad de unos $15-20 \mathrm{~km} / \mathrm{h}$. El fuego se estuvo alimentando con carbón durante unas dos horas, dejando luego que se fuera apagando lentamente.

El resultado fue un fracaso en parte. En las condiciones de trabajo el mineral no llegó a reducirse y muchos fragmentos permanecieron prácticamente intactos. Unos pocos, sin embargo, se habían fundido y formaban agregados de mayor tamaño. El estudio microscópico demostró que, efectivamente, se habían producidos granos y filamentos de cobre. El hecho de que el cobre alcanzara la temperatura de fusión (cerca de $1.100^{\circ} \mathrm{C}$ ) y se difundiera en las grietas indica que conseguir una elevada temperatura no fue el problema principal. Fueron las condiciones ambientales excesivamente oxidantes las responsables del bajo rendimiento de la transformación. No obstante, quedaba demostrado que de una forma muy simple, en una sencilla hoguera bien aireada, se podía obtener cobre aunque no de forma rentable.

Otros tres experimentos fueron realizados en la región minero-metalúrgica prehistórica de Kargaly (Orenburg, Rusia), durante la campaña de trabajo de campo del equipo hispano-ruso en 1998 (Rovira, 1999: 104-107) (5). En esta ocasión no se usaron vasijas de cerámica sino simples cubetas excavadas en el suelo arcilloso del lugar, con la forma de recipientes de tamaños comprendidos entre 30 y $15 \mathrm{~cm}$ de diámetro. Se utilizó mineral de Kargaly (impregnaciones de malaquita y azurita en arenisca), molido hasta porciones de 2-3 mm como máximo y el polvo resultante de esta operación. La ri-

(4) Los resultados completos de este experimento van a ser publicados en breve por Rovira (e.p.b).

(5) En el marco del proyecto DGICYT: PS95-0031, El inicio de la Economía Productiva en la gran estepa eurasiática y su impacto en el medio ambiente: ¿catástrofes ecológicas en la estepa?, dirigido por $\mathrm{M}^{\mathrm{a}}$ Isabel Martínez Navarrete (CSIC). queza media del mineral se estimó en un 10-15\% de cobre. La cavidad fue precalentada con carbón avivado por el flujo de dos toberas alimentadas por fuelles accionados manualmente, de 30 litros de aire de capacidad. El tiempo de precaldeo fue de algo más de media hora, hasta que el carbón encendido alcanzaba su máximo brillo y las zonas bajas de la cubeta se ponían de color rojo cereza. Entonces se iniciaba la reducción agregando un puñado de mineral a la superficie de carbón al rojo blanco, que era inmediatamente cubierta con carbón machacado y carbón en pedazos mayores. Cuando de nuevo ardía vivamente todo el sistema se añadía un nuevo puñado de mineral y se repetía el proceso. La carga de mineral total osciló entre 150 y $300 \mathrm{~g}$. La reducción duraba entre dos y tres horas (dependiendo del tamaño de la cubeta y de la cantidad de mineral).

El resultado final fue el mismo en todos los casos. Se consiguió una masa de escoria bastante ligera, en la que había numerosas bolitas de cobre de un tamaño máximo de $3 \mathrm{~mm}$ (véanse los aspectos analíticos en Rovira 1999: 105). Esta escoria se pulverizaba fácilmente y se podía separar el metal, incluso granos microscópicos, mediante lavado con agua en una palangana. Con el cobre obtenido de fundió un pequeño lingote planoconvexo en un segundo paso.

En el sur de Francia se han realizado varios ensayos de metalurgia experimental a partir de los indicios proporcionados por las vasijas de reducción encontradas en Al Claus (cf. infra, párrafo 41) y de otros restos de metalurgia calcolítica que recordaban técnicas cercanas a las antes descritas. Por lo que se refiere a los primeros (trabajos de J. Happ y L. Carozza, y L. Carozza, B. Mille y D. Bourgarit), los resultados no han dado lugar a su publicación. En cambio los últimos experimentos llevado a cabo en Cabrières (Ambert et al., 1997) han demostrado que era posible conseguir la segregación de cobre metálico desde la fase de tostación (los minerales de Cabrières son sulfuros de cobre) bajo ciertas condiciones que son las mismas que condicionan el funcionamiento de las vasijas de reducción españolas. En efecto, aunque la demostración está todavía incompleta y escasea el mineral ad hoc para continuarla porque las mineralizaciones de la zona están prácticamente agotadas, la reducción parcial de una mezcla de minerales sulfurados y de óxidos, finamente triturados y mezclados a su vez con carbón machacado del mismo tamaño de grano, ha dado resultados probatorios. El

T. P., 59, n. ${ }^{\circ} 1,2002$ 
reciente descubrimiento del poblado de la Capitelle de Broum (Ambert et al., e.p.) prueba que los pobladores calcolíticos del distrito minero de Cabrières utilizaban una técnica muy similar a la de los usuarios de los vasos de reducción españoles.

\section{EL ESTADO DE LA CUESTIÓN EN FRANCIA MERIDIONAL}

La investigación está mucho menos avanzada que en España. El interés por el tema surgió tras veinte años de trabajos en el distrito minero de Cabrières (Ambert, 1995) y con las investigaciones y reflexiones regionales o internacionales iniciadas hace pocos años con investigadores de Alemania y España. A partir de ello se ha podido ver que varios sitios y sus materiales metalúrgicos del Calcolítico y de la Edad del Bronce demuestran la existencia en Francia de vasijas de reducción (Fig. 2).

\subsection{Las principales vasijas de reducción calco- líticas reconocidas en Francia}

El sitio de Al Claus (Tarn y Garonne) representa el ejemplo mejor documentado de la utilización de vasijas de reducción en el Midi francés (Fig. 2,1). La vocación metalúrgica de este yacimiento de finales del Calcolítico (3855 \pm 45 BP, 2448-2175 cal $\mathrm{AC} \mathrm{a} 1 \sigma, \mathrm{Ly}-7272$ ) se hace patente de manera más particular por el hallazgo de 26 fragmentos de cerámica que tienen una costra metálica escorificada, poco espesa, afectando a su superficie interna (Lám. VI) (Carozza, 1998). Forman parte de un lote de 1.600 fragmentos de vasijas de grandes dimen-

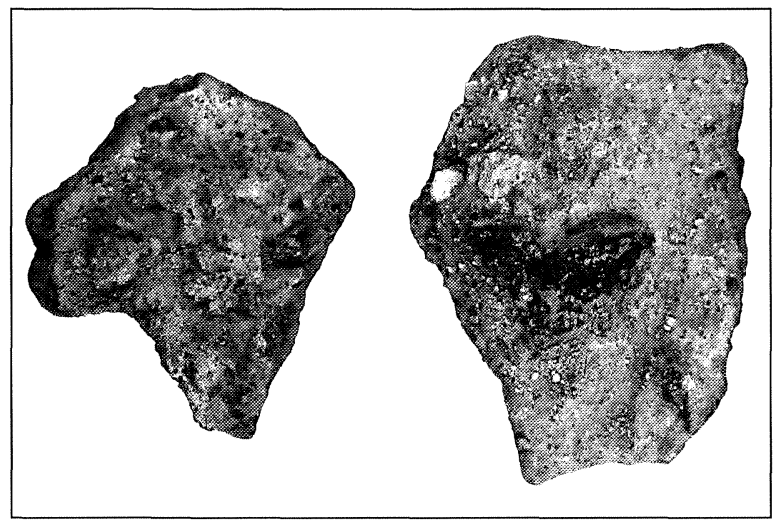

Lám. VI. Fragmentos de vasijas con escorificaciones del yacimiento de $\mathrm{Al}$ Claus.

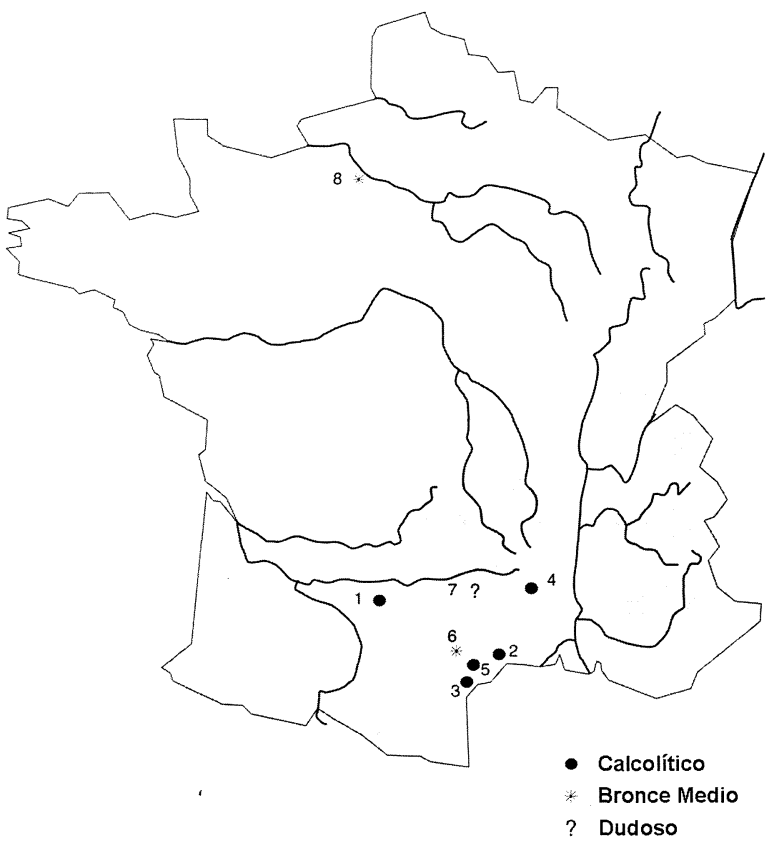

Fig. 2. Mapa con la localización de yacimientos franceses mencionados en el texto: 1 . Al Claus, 2. Travers des Fourches, 3. Ouveillan, 4. Serre de Boidons, 5. Cabriers, 6. Gruta de Bonnefont, 7. Cueva de Cimitière, 8. Fort-Harrouard.

siones pertenecientes a un mismo tipo. Sus características permiten asimilarlos a los de las vasijas de reducción españolas, puesto que las escorificaciones indican un uso metalúrgico específico. Los estudios de laboratorio (Carozza et al., 1997) demuestran que las trazas de vidriado se van perdiendo a medida que se alejan de la pared interna del recipiente, particularidad específica de las vasijas-horno. Con todo, existe una diferencia esencial con las españolas: en ellas se han procesado minerales sulfurados, sin duda de origen regional, ricos en hierro, es decir, calcopirita $\left(\mathrm{CuFeS}_{2}\right)$, mientras que en España sólo se empleaban entonces minerales carbonatados, más fáciles de reducir. La mayor dificultad de aprovechamiento de las menas sulfuradas no debe, sin embargo, ser sobrevalorada si tomamos en cuenta los resultados positivos de los trabajos experimentales realizados con mezclas de carbonatos y sulfuros por Rostoker y Dvorak (1991) y los obtenidos de los trabajos arqueológicos y experimentales relacionados con la metalurgia de Cabrières.

El yacimiento campaniforme de Travers des Fourches (Fig. 2, 2) en Villeveyrac-Hérault (Montjardin, 1996) ha dado tres fragmentos de dos vasos decorados diferentes, que tienen en su cara interna 


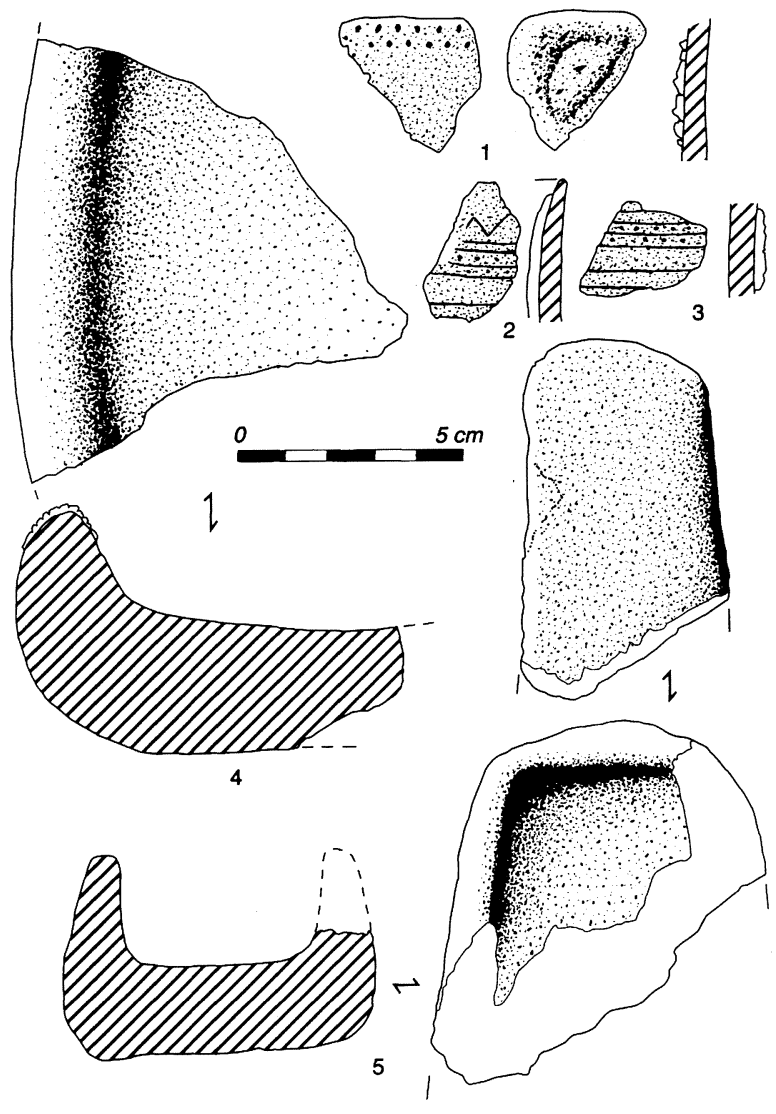

Fig. 3. 1-3 Fragmentos de vasos campaniformes con depósitos escoriáceos en su cara interna de Travers des Fourches, Villeveyrac-Hérault (según Montjardin, 1996). 4 fragmento de brasero con depósito metálico de Bonnefond, Hérault. 5 "lingotera" de Lanuéjols, Lozère (dibujo de J.Y. Boutin). Los otros dibujos son de J. Coularou.

concreciones cuprosas de un mineral no reducido considerado como malaquita (Fig. 3, 1-3). La presencia de una segregación de cobre en el seno de un mineral escorificado, parcialmente reducido (véase Tab. 1) permite ponerlos en relación con los fragmentos campaniformes españoles atribuidos a vasijas de reducción.

En los sitios veracienses de Ouveillan (Fig. 2,3) hay numerosos indicios de actividad metalúrgica: malaquita, residuos cuprosos y fragmentos de escoria (muchos de ellos con una cara curvilínea que pueden ser atribuidos a depósitos escoriáceos internos de crisol o vasija). Macroscópicamente las dos caras de éstos últimos son muy diferentes: la curva es casi lisa y la otra mamelonada. La arcilla que cubría un fragmento estaba cocida y contenía porciones de cobre perceptibles a simple vista. Las impurezas que se han detectado (Tab. 1, Bou 1, 2, 3 ), aunque pequeñas, no se oponen a la gran probabilidad existente de que se practicara una metalurgia calcolítica in situ a partir de los carbonatos analizados. Por otro lado, el gran radio de curvatura de la cara convexa de las escorias remite a su formación en una vasija de reducción.

La excavación de la "cabaña" 3 del poblado calcolítico de Serre de Boidons en Grospierres-Ardèche (Fig. 2,4) ha proporcionado una documentación metalúrgica de las más preciosas del sur de Francia (Gros y Gros 1997: fig. 4) (Fig. 4). Los autores mencionan, entre otros numerosos fragmentos de crisoles, dos "d'une sorte de brique très épaisse à légers rebords portant une encoche à la base" (Fig. 4-2 y3) que nos recuerdan las "lingoteras" de Zambujal (Sangmeister 1995: fig. 11 y 12) y una tobera de pequeño tamaño $(5 \mathrm{~cm}$ de longitud $)$ (Fig. 4-1). Se han efectuado dos análisis a las escorificaciones adheridas a dos crisoles (Tab. 1). Una indica la asociación antimonio (3\%)-plata (2\%) típica de las metalurgias (Ambert 1996) y minerales (Leblanc, 1997) del Midi de Francia. Si bien se impone un estudio renovado de esta documentación para establecer la cadena de procesos metalúrgicos practicada por estos pobladores calcolíticos, la filiación con las vasijas-horno reposa, sin embargo, en la presencia de los fragmentos de lingotera, un objeto presentado en Iberia como una variación morfológica de la vasija de reducción (6). Este tipo de recipiente, a veces de gran tamaño, de fondo plano o ligeramente curvilíneo, con o sin pie, puede presentar en su cara interna las concreciones metálicas propias de las vasijas-horno.

Subrayaremos finalmente que en los sitios metalúrgicos del distrito minero de Cabrières (Fig. 2, 5) no se ha descubierto ningún fragmento de vasija de reducción. No obstante, esta primera metalurgia del Languedoc está estrechamente emparentada con la técnica ibérica puesta en evidencia. En el estado de nuestros conocimientos podemos suponer que las vasijas de reducción fueron introducidas en Francia en una segunda fase metalúrgica (¿contemporánea de los vasos campaniformes y las puntas de Palmela?), con posterioridad a las primeras manifestaciones metalúrgicas reconocidas en Cabrières (Ambert, 1995).

(6) Véase también lo dicho antes en relación con los materiales de Cabezo Juré (párrafo 2.2). Se encuentran representados en Nocete (2001: lám. 17).

T. P., 59, n. ${ }^{\circ} 1,2002$ 


\begin{tabular}{|l|l|c|c|c|c|c|c|c|c|c|c|c|}
\hline DOC & SITE & Cu & Sn & Pb & As & Sb & Ag & Ni & Bi & Fe & Zn & Si \\
\hline Nod & Trav & XXX & 0,001 & - & - & 0,01 & 0,15 & - & - & 0,5 & - & nd \\
\hline Mal & Bou 1 & 47,7 & 0,05 & 0,025 & $\operatorname{Tr}$ & - & 0,002 & 0,002 & - & 3 & - & \\
\hline Sc-Vf & Bou 2 & 7,7 & - & - & 0,005 & $\operatorname{tr}$ & 0,001 & 0,4 & - & XXX & 0,1 & \\
\hline Mal & Bou 3 & 47,8 & 0,02 & 0,025 & - & - & 0,01 & $\operatorname{tr}$ & - & 0,2 & - & 1,06 \\
\hline Mal & Cour & 35,2 & 0,003 & $\operatorname{tr}$ & $\operatorname{Tr}$ & $? 6$ & 0,05 & - & - & 1,4 & 0,15 & 29,4 \\
\hline Sc & S.B. & 38,2 & - & 0,008 & 0,25 & $? 3$ & $? 2$ & 0,02 & $\operatorname{tr}$ & 0,05 & $\operatorname{tr}$ & \\
\hline Sc. & Bonf & 32,4 & - & - & 0,002 & - & - & 0,005 & $\operatorname{tr}$ & $? 6$ & 0,001 & 39,5 \\
\hline
\end{tabular}

Tab. 1. Análisis espectrográfico de materiales asociados a vasijas de reducción francesas (\% en peso).

Abreviaturas: nod nódulo de cobre; Mal malaquita; Sc depósito escoriáceo de crisol; Sc-Vf depósito escoriáceo en vasija de reducción; Trav Travers des Fourches; Bou Bousquet (Ouveillan); Cour Les Courondes (Ouveillan); S.B. Serre de Boidons; Bonf Gruta de Bonnefond.

Nota: Los contenidos de cobre han sido valorados por gravimetría. El resto de los elementos por espectrografía de emisión: X elemento mayor, XX elemento importante, XXX elemento principal, aproximadamente, tr inferior a $0,001 \%,-$ no detectado, nd no medido.

\subsection{Vasijas de reducción y relacionadas atribuibles a la Edad del Bronce}

Un "brasero" fue encontrado en la base del estrato I de la gruta de Bonnefont (Saint-Etienne d'Albagnan-Hérault) (Fig. 2, 6), atribuible al Bronce Final (Guiraud, 1957 y 1964). Ovoide, de fondo plano y grandes dimensiones, presenta depósitos escoriáceos en uno de sus bordes (Fig. 3, 4) que lo relacionan con las vasijas de reducción (Tab. 1).

La cueva de Cimetière (Lanuéjols-Gard) ha proporcionado un grueso fragmento de cerámica rectangular con los ángulos redondeados (Fig. 3, 5), en un sedimento revuelto. Recuerda las lingoteras de Portugal. Atribuible al Calcolítico o al Bronce Antiguo, no presenta signos de escorificación metálica.

La metalurgia de Fort-Harrouard (Fig. 2, 8), divulgada por los trabajos de J.P. Mohen (Mohen y Bailloud, 1987; Mohen, 1990: 121), es de finales del Bronce Final. Entre los numerosos objetos relacionados con la metalurgia se encontró un recipiente con fondo plano de grandes dimensiones (40 $\mathrm{cm}$ de diámetro, $15 \mathrm{~cm}$ de altura), denominado horno-crisol por Mohen y Walter (1994: fig. 2). Posee al nivel del cuello dos picos vertedores simétricos. La panza presenta numerosas líneas de perforaciones y tiene en el interior un recubrimiento "de plusieurs couches d'argile vitrifiée qui intègrent en particulier de nombreux nodules de cuivre et des structures riches en étain" (Mohen y Walter, 1994). Del estudio realizado por estos autores se pueden extraer diferencias técnicas evidentes entre las vasijas para reducir minerales de cobre francoespañolas y este objeto de Fort-Harrouard. Los análisis indican la producción reiterada de aleaciones binarias y ternarias (cobre-plomo-estaño). También es propio de un crisol de ese tamaño la reparación del interior con una nueva capa de arcilla entre dos fusiones. Al contrario que en las vasijashorno, en él se reciclaban metales, como lo demuestran los cristales con forma de agujas romboidales presentes, propios del óxido de estaño que se forma por corrosión del bronce. Este recipiente sirvió, pues, para fundir y alear los metales y no los minerales (característica de las vasijas-horno). Los experimentos realizados por J.P. Mohen comprobaron, por otro lado, su carácter de crisol usado para preparar la aleación.

\section{CONCLUSIONES}

Cuatro puntos constituyen los ejes cardinales de nuestras conclusiones:

1. El mapa de distribución de las vasijas de reducción de minerales de cobre atestigua la gran difusión espacial de esta técnica metalúrgica en la Península Ibérica. Ante la ausencia de otros procedimientos metalúrgicos, puede ser considerada como el único método de obtención de cobre en la Prehistoria reciente española. En efecto, las vasijashorno reinaron no solamente en el Calcolítico sino 


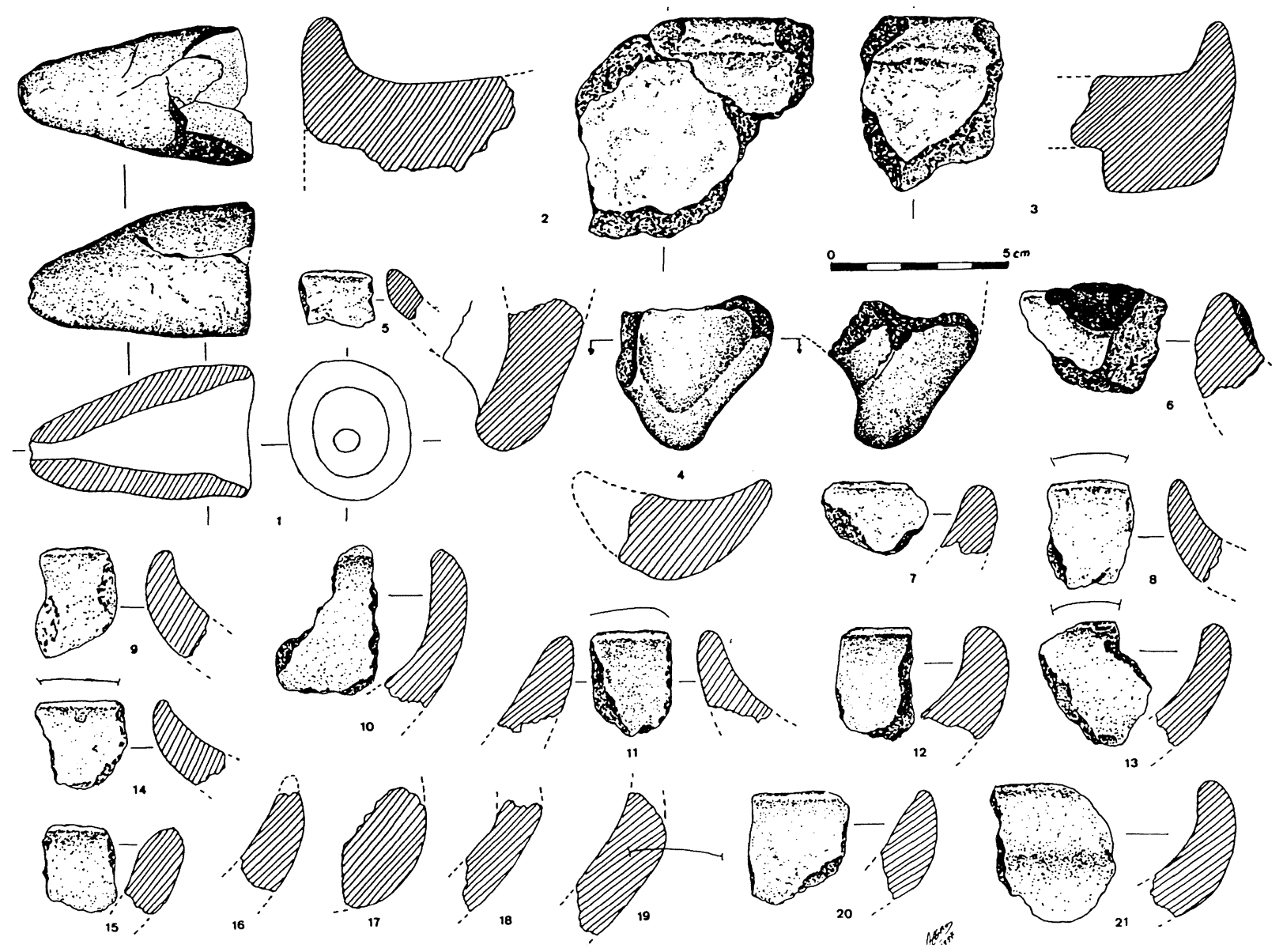

Fig. 4. Utillaje de los metalúrgicos calcolíticos de la cabaña 3 de Serre de Boidons, Ardèche (según Gros y Gros, 1997).

que fueron utilizadas desde el Neolítico (Cerro Virtud) hasta la Edad del Hierro (Gómez Ramos, 1996b). Algunas regiones están bien provistas de evidencias (Madrid, Cataluña y el Sureste) (Fig. 1). Estas concentraciones son consecuencia más bien del estado de nuestros conocimientos que de una distribución real. El yacimiento de la Bauma del Serrat del Pont no es sólo el yacimiento más septentrional de entre ellos sino también el sitio que ha proporcionado el mayor número de fragmentos (65) de estas vasijas en España. Es una buena cabeza de puente en dirección a algunos yacimientos registrados en el sur de Francia.

2. De los sitios con vasijas de reducción de la Francia meridional, el de Al Claus es el mejor documentado (Carozza 1998). La metalurgia del yacimiento campaniforme de Travers des Fourches también recuerda la española con sus numerosos fragmentos. El recipiente con escorificaciones de Bonnefont y la serie de Serre de Boidons refuerzan la presencia en Francia de esta tecnología. Las vasijas de reducción de minerales de cobre no fueron sistemáticamente utilizadas en las primeras fases de la metalurgia del sur de Francia. En los principales yacimientos metalúrgicos del distrito minero de Cabrières (Roque-Fenestre, La Capitelle de Broum) fueron reemplazados por cubetas excavadas poco profundas que se llenaban de una mezcla de minerales (óxidos y sulfuros) y carbón de madera, todos bien machacados. Esta técnica tan parecida a la de las vasijas servía para obtener un metal de buena calidad que cubrió las necesidades de una gran parte del Midi de Francia (Ambert, 1995 y 1999). Así, según el estado de nuestros conocimientos, cabe pensar que la posible introducción en Francia de las vasijas de reducción tuvo lugar con posterioridad a la metalurgia de Cabrières.

3. Las principales diferencias entre las metalurgias de España y Francia meridional surgen de los minerales trabajados: casi exclusivamente carbona- 
tos y óxidos en España, sulfuros y óxidos en Cabrières y Al Claus. Esta diferencia, que tiene indudables repercusiones tanto en lo que se refiere al funcionamiento del proceso de producción de metal como a la calidad de los metales obtenidos, es el eje de nuestras preocupaciones actuales.

4. Queda finalmente por subrayar que, si bien la metalurgia de la vasija de reducción es una técnica ibérica infiltrada en Francia, también fue utilizada bajo diversas formas por otras metalurgias antiguas, como en Abu Matar (Tylecote et al., 1974) y Shiqim (Shalev y Northover, 1987) en Israel y Feinan en Jordania (Hauptmann et al., 1996). Traspasa de hecho ampliamente las fronteras del Viejo Mundo, como lo atestigua el fundidor de hachas mexicano que ilustra la cubierta del libro Métallurgie Préhistorique (Mohen, 1990). Dicha viñeta muestra la transformación, en una vasija-horno, del mineral en objeto de metal en una sola fase.

\section{AGRADECIMIENTOS}

Este trabajo ha sido realizado en el marco de las Acciones Integradas entre Francia (PAI Picasso, Université de Toulouse) y España (Universidad de Valladolid), dedicadas en particular al estudio de las vasijas para reducir minerales de cobre. Queremos expresar aquí nuestro agradecimiento a J. Vaquer y G. Delibes de Castro, responsables de este convenio, así como a nuestros colegas D. Bourgarit, B. Mille, J. Coularou e I. Montero. También se ha beneficiado igualmente de las investigaciones llevadas a cabo desde 1996 por el PCR "Mines et métallurgies préhistoriques du Midi de la France". Moisés Rodríguez Bayona colaboró en la preparación de algunas muestras de Almizaraque para metalografía.

\section{BIBLIOGRAFÍA}

Alcalde, G.; Molist, M.; Montero, I.; Planagumà, Ll. y Toledo, A. (1998): "Producciones metalúrgicas en el Nordeste de la Península Ibérica durante el III milenio cal. AC: el taller de la Bauma del Serrat del Pont (Tortellà, Girona)". Trabajos de Prehistoria 55(1): 81-100.

Ambert, P. (1995): "Les mines préhistoriques de Cabrières (Hérault): Quinze ans de recherches. Etat de la question". Bulletin de la Société Préhistorique Française 3: 499-508.

- (1997): "Recherches sur les fours de métallurgistes chalcolithiques et de l'Age du Bronze d'Europe Occi- dentale (domaines méditerranéens et alpins). Etat de la Question. Perspectives de recherches". Archéologie en Languedoc 21: 29-49.

- (1998): "Métallurgie préhistorique, métallurgie expérimentale, les fours, état de la question, perspectives de recherches". En M.Ch. Frère-Sautot (ed.): Paléométallurgie des Cuivres. Actes du colloque de Bourg-enBresse et Beaune, 17-18 oct. 1997. Éditions Monique Mergoil. Montagnac: 1-16.

- (1999): "Les minerais de cuivre et les objets métalliques en cuivre à antimoine-argent du sud de la France. Preuves d'une exploitation minière et métallurgique du début du III ${ }^{\circ}$ millénaire B.C". En A. Hauptmann, E. Pernicka, Th. Rehren y Ü. Yalçin (eds.): The Beginnings of Metallurgy. Proceedings of the International Conference. Bochum, 1995. Der Aschnitt., B. 9: 177194.

Ambert, P.; Bourgarit, D.; Mille, B.; Carozza, L. y HapP, J. (1997): "Un nouveau point sur l'expérimentation des cuivres gris dans le Midi de la France". Archéologie en Languedoc 21: 45-50.

Ambert, P.; Coularou, J.; Cert, C.; Guendon, J.L.; BourGarit, D.; Mille, B.; Dainat, D.; Houles, N. y Baumes, B. (e.p.): "Le plus vielle établissement de métallurgistes de France (III ${ }^{\circ}$ millénaire avant J.C.), Péret-Hérault". C.R. Academie des Sciencies, 332, 2002.

Bourgarit, D. y Mille, B. (1997): "La métallurgie chalcolithique de Cabrières: confortation des données expérimentales et archéologiques en laboratoire". Archéologie en Languedoc 21: 51-64.

BRIARD. J. (1992): "Paléométallurgie armoricaine. Lingots en plomb du Bronze final et creusets protohistoriques". Antiquités Nationales 22/23: 37-42.

CARozZA, L. (1998): “Analyse et interprétation des témoins de métallurgie Chalcolithique découverts dans l'habitat d'Al Claus (Tarn-et-Garonne)". En M.Ch. FrèreSautot (ed.): Paléométallurgie des Cuivres. Actes du colloque de Bourg-en-Bresse et Beaune, 17-18 oct. 1997. Éditions Monique Mergoil. Montagnac: 45-51.

Carozza, L.; Bourgarit, D.; Mille, B. y Burens. A. (1997): "L'habitat et l'atelier de métallurgiste chalcolithique d'Al Claus". Archéologie en Languedoc 21: 147-160.

COMENDADOR Rey, B. (1998): Los inicios de la metalurgia en el noroeste de la Península Ibérica. Brigantium, 11, Museo Arqueolóxico e histórico Castelo de San Antón, A. Coruña.

Delibes, G.; Díaz-Andreu, M.; Fernández-Posse, M. ${ }^{a} D$.; Martín, C.; Montero, I.; MuÑoz, K. y Ruiz, A. (1996): "Poblamiento y desarrollo cultural en la Cuenca de Vera durante la Prehistoria Reciente". Complutum Extra, 6(1): 153-170.

Delibes, G.; Fernández-Miranda, M.; Fernández-Posse, M.D.; Martín, C.; Montero, I. y Rovira, S. (1991): "Almizaraque (Almería, Spain). Archaeometallurgy during the Chalcolithic in the South-East of the Iberian 
Peninsula". En Ch. Éluère y J.P. Mohen (ed.): Découverte du Métal. Picard. París: 303-315.

Delibes, G.; Fernández-Miranda, M.; Fernández-Posse, M.D.; Martín, C.; Rovira, S. y SAnZ, M. (1989): “Almizaraque (Almería): Minería y metalurgia calcolíticas en el Sureste de la Península Ibérica". En C. Domergue (coord.): Minería y Metalurgia de las Antiguas Civilizaciones Mediterráneas y Europeas (I). Ministerio de Cultura. Madrid: 81-96.

Delibes, G. y Montero, I. (1997): "Els inicis de la metal-lúrgia a la Península Ibèrica. Transferència de tecnologia o descobriment autònom? CotaZero 13: 19-28.

- (coord.) (1999): Las Primeras Etapas Metalúrgicas en la Península Ibérica. II. Estudios Regionales. Instituto Universitario Ortega y Gasset y Ministerio de Educación y Cultura. Madrid.

Fernández-Miranda, M.; Montero, I. y Rovira, S. (1995): "Los primeros objetos de bronce en el occidente de Europa". Trabajos de Prehistoria 52(1): 57-69.

Fernández-Posse, M.D.; Montero, I.; SÁnchez-Palencia, F.J. y Rovira, S. (1993): "Espacio y metalurgia en la Cultura Castreña: la zona arqueológica de Las Médulas". Trabajos de Prehistoria 50: 197-220.

Gómez Ramos, P. (1996a): “¿Dónde están las toberas de la Edad del Bronce de la Península Ibérica?" Acontia 2: 209-215.

- (1996b): "Hornos de reducción de cobre y bronce en la Pre y Protohistoria de la Península Ibérica". Trabajos de Prehistoria 53(1): 127-143.

- (1998): "Estudio preliminar de vasijas de reducción y crisoles inéditos del yacimiento campaniforme del Camino de la Yesera (Getafe, Madrid)". Cuadernos de Prehistoria y Arqueología. Universidad Autónoma de Madrid 25(1): 119-134.

- (1999): Obtención de Metales en la Prehistoria de la Península Ibérica. BAR International Series 753. Archaeopress. Oxford.

Gómez Ramos, P.; Montero, I. y Rovira, S. (1999): "La metalurgia prehistórica en la Sierra de Aracena (Huelva)". XII Jornadas del Patrimonio de la Comarca de la Sierra. Aracena, marzo de 1997: 237-253. Huelva.

Gros, A.C. y Gros, O. (1997): "Vingt ans de recherches préhistoriques à Grospierres (Ardèche) et dans les environs. Les sites chalcolithiques et les débuts de la métallurgie". Ardèche Archéologie 14: 17-36.

Guiraud, R. (1957): "Les grottes de Bonnefont (SaintEtienne d'Albagnan, Hérault)". Cahiers Ligures de Préhistoire et d'Archéologie 6: 3-30.

- (1964): Le Peuplement du Bassin de l'Orb des Origines à l'Époque Gallo-Romaine. Imprimerie Espic. Toulouse.

Happ, J.; Ambert, P.; Bourhis, J.R. y Briard, J. (1994): "Premiers essais de métallurgie expérimentale à l'Archéodrome de Beaune à partir des minerais chalcolithiques de Cabrières (Hérault)". Bulletin de la Société Préhistorique Française 91 (6): 429-434.
Hauptmann, A.; Bachmann, H.G. y Maddin, R. (1996): "Chalcolithic copper smelting: new evidence from excavations at Feinan, Jordan". Archaeometry 1994, Ankara. The Proceedings of the $29^{\text {th }}$ International Symposium on Archaeometry. Ankara, 9-14 May 1994. Tübitak. Ankara: 3-10.

Hunt, M. y Hurtado, V. (1999): “Suroeste”. En G. Delibes e I. Montero (coord.): Las Primeras Etapas Metalúrgicas en la Península Ibérica. II. Estudios Regionales. Instituto Universitario Ortega y Gasset y Ministerio de Educación y Cultura. Madrid: 275-331.

Leisner, V. y Schubart, H. (1966): "Die kupferzeitliche Befestigung von Pedro do Ouro, Portugal". Madrider Mitteilungen 7: 9-10.

Mille, B. y Bourgarit, D. (1998): "Du minerai de cuivre sulfuré traité dès le Chalcolithique: les exemples de Cabrières (Hérault) et Al Claus (Tarn \& Garonne)". En M. Ch. Frère-Sautot (ed.): Paléométallurgie des cuivres. Actes du colloque de Bourg-en-Bresse et Beaune, 17 18 oct. 1997. Éditions Monique Mergoil. Montagnac: 27-36.

MoHeń, J.P. (1990): Métallurgie Préhistorique. Introduction à la Paléo-métallurgie. Masson. París.

Mohen, J.P. y BaIlloud, G. (1987): La Vie Quotidienne. Les Fouilles du Fort-Harrouard. L'Age du Bronze en France 4. Picard. París.

Mohen, J.P. y WaLter, P. (1994): "Le four-creuset, une invention inédite de l'Age du Bronze européen”. Techné 1: $103-110$.

Montero, I. (1993): "Bronze Age metallurgy in Southeast Spain”. Antiquity 67: 46-57.

- (1994): El Origen de la Metalurgia en el Sureste Peninsular. Instituto de Estudios Almerienses. Almería.

Montero, I. y Ruiz TaboadA, A. (1996): "Enterramiento colectivo y metalurgia en el yacimiento neolítico de Cerro Virtud (Cuevas de Almanzora, Almería)". Trabajos de Prehistoria 53 (2): 55-75.

MonTJARdin, R. (1996): “L'habitat campaniforme (pyrénaïque) du Travers des Fourches, Veyrac (VilleveyracHérault), dans le cadre de la chronologie campaniforme". Revue Archéologique de l'Est, Sup. 14: 483-502.

Motos, F. de (1918): La Edad Neolítica en Vélez Blanco. Comisión de Investigaciones Paleontológicas y Prehistóricas, Memoria 19. Madrid.

Nocete, F. (2001): Tercer Milenio Antes de Nuestra Era. Relaciones y contradicciones centro/periferia en el Valle del Guadalquivir. Ediciones Bellaterra, S.L. Barcelona.

ROSTOKER, W. y DVORAK, J.R. (1991): "Some experiments with co-smelting to copper alloys". Archaeomaterials 5: 5-20.

RothenBERG, B. (1985): "Copper smelting furnaces in the Arabah, Israel: The archaeological evidence". En P.T. Craddock y M.J. Hughes (eds.): Furnaces and Smelting Technology in Antiquity. British Museum Occasional Paper 48. Londres: 123-150.

T. P., 59, n. ${ }^{\circ} 1,2002$ 
RoviRA, S. (1989): "Recientes aportaciones para el conocimiento de la metalurgia primitiva en la provincia de Madrid: un yacimiento Campaniforme en Perales del Río (Getafe, Madrid)". Actas del XIX Congreso Nacional de Arqueología (Castellón 1987) I: 355-366. Zaragoza.

- (1999): "Una propuesta metodológica para el estudio de la metalurgia prehistórica: el caso de Gorny en la región de Kargaly (Orenburg, Rusia)". Trabajos de Prehistoria 56(2): 85-113.

- (e.p.a): "The origin and development of metallurgy in Spain". The Begining of the Use of Metals in the Old World. Freiberg Seminar, 18-21 November 1999. University of Freiberg. Freiberg.

- (e.p.b): "Experimentos de fundición de minerales de cobre. Resultados de un primer intento". En Minería y Metalurgia de la Edad del Bronce. Una revisión desde el Valle del Duero. Instituto Rei Alfonso Henriques. Zamora.

Rovira, S. y AMBERT, P. (2002): "Les céramiques à réduire le minerai de cuivre: une technique metallurgique utilisée en Ibérie, son extension en France méridionale. Bulletin de la Société Préhistorique Française 99(1).

Rovira, S. y Gómez Ramos, P. (1998): "Metalurgia calcolítica en Carmona (Sevilla)". Spal 7: 69-79.

Rovira, S. y Montero, I. (1994): "Metalurgia Campaniforme y de la Edad del Bronce en la Comunidad de Madrid". En C. Blasco (ed.): El Horizonte Campaniforme de la Región de Madrid en el Centenario de Ciempozuelos. Universidad Autónoma de Madrid. Madrid: 137-171.

Rovira, S.; Montero, I. y Consuegra, S. (1997): Las Primeras Etapas Metalúrgicas en la Península Ibérica. I. Análisis de Materiales. Instituto Universitario Ortega y Gasset y Ministerio de Educación y Cultura. Madrid.

Rovira, S.; Nocete, F.; SÁez, R. y Nieto, J.M. (2001): “Aspectos preliminares de la metalurgia en el sitio prehistórico de Cabezo Juré (Alosno, Huelva). La producción de objetos de metal". IV Congreso Nacional de Arqueometría (Valencia 2001). Valencia: 182-191.
Ruiz TaboadA, A. y Montero, I. (1999): "The oldest metallurgy in western Europe". Antiquity 73: 897-903.

SÁez, R.; Nieto, J.M.; Nocete, F.; Ruiz Conde, A.; SÁNCHez Soto, P.J. y Rovira, S. (2001): "Estudio químico y mineralógico de escorias calcolíticas de Cabezo Juré (Alosno, Huelva)". IV Congreso Nacional de Arqueometría (Valencia 2001). Valencia: 192-199.

SAngmeister, E. (1995): Zambujal. Kupferfunde aus den Grabungen 1964 bis 1973. Deutsches Archäologisches Institut. Madrid.

Sesma, J. (1995): "Diversidad y complejidad: poblamiento de Navarra en la Edad del Bronce". Cuadernos de Arqueología de la Universidad de Navarra 3: $147-$ 184.

Shalev, S. y Northover, P. (1987): "Chalcolithic metal and metal working from Shiqim”. En T.E. Levy (ed.): Shiqim I. BAR International Series 356. Archaeopress. Oxford: $357-371$

SIRET, L. (1948): "El tell de Almizaraque y sus problemas". Cuadernos de Historia Primitiva III: 117-124.

Siret, E. y Siręt, L. (1890): Las Primeras Edades del Metal en el Sudeste de España. Sin edit. Barcelona.

TyleCote, R.F. (1974): "Can copper be smelted in a crucible?". Journal of the Historical Metallurgy Society 8(1): 54.

Tylecote, R.F.; Rothenberg, B. y Lupu, A. (1974): "The examination of metallurgical material from Abu Matar, Israel". Journal of the Historical Metallurgy Society 8(1): 32-34.

ZWICKER, U. (2000): "Frühe Kupferverhüttung auf Zyfern. Archäometrie und Denkmalpflege". Kurzberichte 2000. 29-31 2 März 2000, Kanonenhof in Dresden. Gesellschaft Deutscher Chemiker. Dresden: 141-143.

ZWicker, U.; Greiner, H.; HofMANN, K.H. y ReITHinger, M. (1985): "Smelting, refining and alloying of copper and copper alloys in crucible-furnaces during prehistoric up to Roman time". En P.T. Craddock y M.J. Hughes (eds.): Furnaces and Smelting Technology in Antiquity. British Museum Occasional Paper 48. Londres: 103115 . 